\title{
molecules
}

ISSN 1420-3049

www.mdpi.com/journal/molecules

Article

\section{Free Radical Scavenging Activity and Anthocyanin Profile of Cabernet Sauvignon Wines from the Balkan Region}

\section{Blaga Radovanović $^{1, *}$ and Aleksandra Radovanović ${ }^{2}$}

1 Department of Chemistry, Faculty of Science and Mathematics, University of Niš, Višegradska 33, P.O.Box 224, 18000 Niš, Serbia

2 Faculty of Chemistry, Studentski trg 12-16, 1100 Belgrade, Serbia, E-Mail: radovanovic911@yahoo.com (A.R.)

* Author to whom correspondence should be addressed; E-Mail: blaga_radovanovic@yahoo.co.uk; Tel.: +381 18 53015; Fax: +381 18533014 .

Received: 20 April 2010; in revised form: 2 June 2010 / Accepted: 7 June 2010 /

Published: 10 June 2010

\begin{abstract}
The present study is focused on anthocyanin derivatives characterizing the antioxidant activity of Cabernet Sauvignon wines produced from different vineyard regions in the Balkans. These bioactive compounds were quantified with a high performance liquid chromatography (HPLC)-diode array detection (DAD) method. The antiradical activity was estimated by the ability of the wine to scavenge the stable 2,2 -diphenyl-1-picrylhydrazyl free radical $\left(\mathrm{DPPH}^{\circ}\right)$. The results show that the total anthocyanin content varied from 205.88 to $1940.28 \mathrm{mg} / \mathrm{L}$, depending on agroclimatic factors and the enological practices of the corresponding vineyard region. The most prominent antocyanin in all investigated Cabernet Sauvignon wines was malvidin-3-O-monoglucoside, which accounted for $50.57 \%$ of total content, followed by its acetyl derivatives, 15.45\%, and p-coumaryl derivatives $5.66 \%$. The relationship between the anthocyanin derivatives and free radical scavenging activity is discussed. A high correlation between total anthocyanin content and DPPH scavenging ability of tested wines was confirmed $\left(r^{2}=0.9619\right)$. The significant correlations were obtained between antiradical activity and the sum of 3-monoglucoside $\left(r^{2}=0.95594\right)$, the sum of 3-acetyl-3-glucoside $\left(r^{2}=0.9728\right)$ and the sum of $p$-coumaryl-3-glucoside $\left(\mathrm{r}^{2}=0.8873\right)$ of wine samples. It can be concluded that, the anthocyanin composition can be used as biochemical marker for the authenticity of red grape cultivar and their corresponding single-cultivar wine.
\end{abstract}


Keywords: Cabernet Sauvignon wines; anthocyanins; free radical scavenging activity; HPLC

\section{Introduction}

Anthocyanins, extracted from the skins of grapes during crushing, pressing, and fermentation are major components responsible for red wine color. The concentration and composition of anthocyanins in red wine grapes vary with species, variety, season, and a wide range of environmental and management factors such as climate, soil conditions and weather. Significant differences in anthocyanin concentration between sun exposed and shaded clusters of Cabernet Sauvignon grape were found by Crippen and Morrison [1].

On the other hand, winemaking conditions play an important role in the extraction of anthocyanins from grape and in their further stability in wine: the time of maceration and fermentation in contact with the grape skins and seeds, pressing, maturation, fining and aging conditions [2,29].

Wine consists of different phenolic compounds, so the antioxidant and the biological activity of wine are connected with a synergy of these compounds. Recent studies indicate that consumption of the small amounts of red wine on a regular base reduce the risk of coronary heart disease, and atherosclerosis, and this benefit is ascribed to the antioxidant properties of the polyphenolic compounds $[3,4]$. Still, it is very important to determine which group of phenolic compounds is most influential in these properties of wine. In both, in vitro and in vivo research trials, anthocyanins have demonstrated noticeable ability to reduce cancer cell proliferation and to inhibit tumor formation [5-7]. Finally, the higher is the concentration of phenolic compounds in wines, the higher will be theirs antioxidant capacity and antimicrobial activity [8-11]. In recent years, evidence has accumulated suggesting that wine may be one of the most prominent elements that contribute to the beneficial health effect of the so-called "the Mediterranean diet" [12].

Although various classes of polyphenols have been thoroughly studied with respect to their impact on quality of wines, only relatively recently have anthocyanin components gained increasing interest as nutritional antioxidants. This suggests that the anthocyanin profile, defined as the percentage content of each anthocyanin, is less strongly modified by environmental factors, such as soil irrigation, exposure to sun, degree of ripening of the grape, and can be used for verifying the varietal authenticity of grapes and their corresponding single-cultivar wines. The use of statistical models created on the basis of percentage values of singular anthocyanins has given good results in the chemotaxonomic classification of grapes of different varieties and from various geographical areas [13]. Anthocyanins are accumulated in cell vacuoles and are responsible for diverse pigmentation from orange to red, purple and blue in flowers, fruits and vegetables. Due to presence of eight conjugated double bonds carrying a positive charge, anthocyanins are intensely red or orange under acidic conditions (below $\mathrm{pH} 2$ ), but in higher $\mathrm{pH}$ they are colorless and in alkaline conditions change their colour into bluish. Intensity and type of the color of anthocyanins is affected by the number of hydroxyl and methoxyl groups: if more hydroxyl groups, then the color goes toward a more bluish shade; if more methoxyl groups, then redness is increased [14]. 
Cabernet Sauvignon is the world`s most widely recognized red wine grape variety. From France, the grape spread across Europe, New World and to South Africa. Despite its importance in the world of wine, the grape is a relatively new variety, being the product of a chance crossing between Cabernet Franc and Sauvignon Blanc sometime during the $17^{\text {th }}$ century in southwestern France.

The Balkan region has some good modern vineyards, 80 per cent of which are planted with red wine grapes, including Cabernet Sauvignon and Merlot, as well as the indigenous grapes. Considering the economic importance of winemaking in the Balkan countries, the aim of this work was to evaluate the free radical scavenging activity of eighth Cabernet Sauvignon wines produced from different agronomical and winemaking regions, and their correlation with the total and the real content of the main anthocyanin derivatives.

\section{Results and Discussion}

\subsection{The content and the distribution of anthocyanins in Cabernet Sauvignon wine samples}

Anthocyanin composition is an important quality parameter for red grapes because of the significance of these compounds in determining color of the resulting wines [14]. All investigated Cabernet Sauvignon wines produced from different vineyards in the Balkan region are listed in Table 1.

Table 1. The wine samples studied.

\begin{tabular}{lll}
\hline Wine code & Wine and vintage & Wine producer \\
\hline I & Cabernet Sauvignon- Mezzek, 2007 & Katarzyka Estate (Bulgaria) \\
II & Cabernet Saugnon, 2007 & Laguna (Poreč, Croatia) \\
III & Cabernet Sauvignon, 2007 & Plantaža (Montenegro) \\
IV & Cabernet Sauvignon - Alexandria, 2007 & Tikveš (Macedonia) \\
V & Cabernet Sauvignon - Oplenac, 2008 & Cellars of King, (Oplenac, Serbia) \\
VI & Cabernet Sauvignon - Terra Lazarica, 2007 & Rubin (Kruševac, Serbia) \\
VII & Cabernet Sauvignon, 2008 & Radmilovac (Belgrade, Serbia) \\
VIII & Cabernet Sauvignon, 2008 & Cevin (Niš, Serbia) \\
\hline
\end{tabular}

The red wines from the Balkan region were found to contain significantly higher amounts of anthocyanins $[10,12,24]$. The changes in content of anthocyanin composition and radical scavenging activity in investigated Cabernet Sauvignon wine samples are presented in Table 2. The total content of anthocyanins varied from $205.88 \mathrm{mg} / \mathrm{L}$ (Cabernet Sauvignon - Terra Lazarica, No. VI, Table 1.) to $940.28 \mathrm{mg} / \mathrm{L}$ (Cabernet Sauvignon- Oplenac, No. V, Table 1.), the average value being $1073.08 \mathrm{mg} / \mathrm{L}$. High concentration of anthocyanins in Cabernet Sauvignon grape is essential for good color in Cabernet Sauvignon wine. There are numerous viticulture factors that affect grape anthocyanin content [17-20]. Light exposure to grape clusters and berry size are two of the most important [1]. The results obtained confirm a variation in the anthocyanin composition of wine samples tested. The range of the data obtained is in agreement with the available literature [15-20].

Monomeric anthocyanins are the most labile phenolic compounds in wine, typically decreasing at a rate of about $50 \%$ per year $[14,25]$. Anthocyanin extraction and stability are affected by winery 
production practices. Monomeric anthocyanins usually decline during fermentation and maceration, but the process may continue throughout the life of a wine. Wine characteristics such as $\mathrm{pH}, \mathrm{SO}_{2}$, and acetaldehyde influence these processes and anthocyanin interactions with other phenolic compounds. Stability of anthocyanins can be enhanced through so called copigmentation. Copigmentation plays a crucial role in wine ageing and maturation. Acylated anthocyanins containing two or more aromatic acyl groups may affect the color through a mechanism called intramolecular copigmentation [19,20].

Anthocyanins also interact with other flavonoids and related compounds to produce an increase in color intensity and a shift in the wavelength of maximum absorbance toward higher wavelengths. Such a phenomenon is called intermolecular copigmentation, which can take place in acidic, neutral and even slightly alkaline aqueous solution. Polymeric anthocyanin content of the Cabernet sauvignon wine samples from the 2007 and 2008 vintage seasons (Table 2), using the pH-differential method [21] was determined from 45.50 to $69.77 \%$. As wines age, a greater proportion of their anthocyanin content is polymerized, then color density varied from 6.76 to 11.56 (mean 7.16) and hue from 0.62 to 1.12 (mean 0.96) absorbance units.

Table 2. Some analytical data, content of anthocyanins and radical scavenging activity of the wine samples.

\begin{tabular}{llllllll}
\hline $\begin{array}{l}\text { Wine } \\
\text { code }\end{array}$ & $\begin{array}{l}\text { Alcohol } \\
\mathbf{( v o l} \mathbf{\% )}\end{array}$ & $\begin{array}{l}\mathbf{p H} \\
\text { value }\end{array}$ & $\begin{array}{l}\text { Total } \\
\text { anthocyanins } \\
\mathbf{( m g / L )}\end{array}$ & $\begin{array}{l}\text { Polymeric } \\
\text { color } \\
\mathbf{( \% )}\end{array}$ & $\begin{array}{l}\text { Color density } \\
\text { (absorbance } \\
\text { units) }\end{array}$ & $\begin{array}{l}\text { Hue } \\
\text { (absorbance } \\
\text { units) }\end{array}$ & $\begin{array}{l}\text { Radical } \\
\text { scavenging } \\
\text { (\%) }\end{array}$ \\
\hline I & 14.0 & 3.67 & $593.36 \pm 2.14$ & $69.08 \pm 0.15$ & $8.44 \pm 0.25$ & $1.11 \pm 1.20$ & $75.05 \pm 1.20$ \\
II & 12.0 & 3.55 & $424.66 \pm 1.45$ & $63.45 \pm 0.23$ & $7.86 \pm 1.02$ & $0.93 \pm 0.45$ & $71.30 \pm 0.45$ \\
III & 12.5 & 3.45 & $505.17 \pm 2.55$ & $65.86 \pm 0.22$ & $8.23 \pm 1.06$ & $1.12 \pm 0.23$ & $72.06 \pm 0.23$ \\
IV & 11.5 & 3.21 & $408.26 \pm 2.09$ & $54.88 \pm 0.22$ & $6.76 \pm 0.25$ & $1.06 \pm 0.16$ & $71.10 \pm 0.16$ \\
V & 13.0 & 3.41 & $1940.28 \pm 2.33$ & $45.50 \pm 0.16$ & $11.56 \pm 0.34$ & $1.03 \pm 0.56$ & $83.53 \pm 0.56$ \\
VI & 11.5 & 3.54 & $205.58 \pm 1.10$ & $69.77 \pm 0.23$ & $6.88 \pm 0.28$ & $0.82 \pm 1.02$ & $70.03 \pm 1.02$ \\
VII & 12.5 & 3.54 & $850.08 \pm 1.45$ & $66.76 \pm 0.17$ & $8.78 \pm 0.15$ & $1.01 \pm 1.12$ & $76.16 \pm 1.12$ \\
VIII & 11.5 & 3.85 & $335.44 \pm 2.05$ & $68.15 \pm 0.13$ & $7.21 \pm 0.24$ & $0.94 \pm 0.75$ & $70.87 \pm 0.75$ \\
\hline
\end{tabular}

\subsection{HPLC analysis of Cabernet Sauvignon wine samples}

Anthocyanins profile of grape and wine, determined by the relative proportions of the different anthocyanins, are characteristic for each grape variety and wine, corresponding. Moreover, concentrations of different compounds can vary significantly within grape cultivars according to environmental conditions and winemaking practices [1,20,29].

Anthocyanins were identified by their retention times, which were compared to standards, since that is their characteristic wavelength. The chromatographic of Cabernet Sauvignon wine sample, Oplenac vineyard region in Serbia monitored at $520 \mathrm{~nm}$ is given in Figure 1. In this chromatogram the peaks 1, 2, 3, 4 and 5 were identified as -3-glucosides: delphinidin- (1), cyanidin- (2), petunidin- (3), peonidin(4) and malvidin-3-glucoside (5); the peaks 6, 7, 8, 9 and 10 were identified as -3-glucoside-acetates: the delphinidin- (6), cyanidin- (7), petunidin- (8), peonidin- (9) and malvidin-3-glucoside acetate (10), and the peaks 11, 12 and 13 were identified as -3-glucoside-p-coumarates: petunidin- (11), peonidin(12) and malvidin-3-glucoside- $p$-coumarate (13): 
Figure 1. HPLC chromatogram of anthocyanins in Cabernet Sauvignon wine from Oplenac viticulture region (Serbia) monitored at $520 \mathrm{~nm}$.

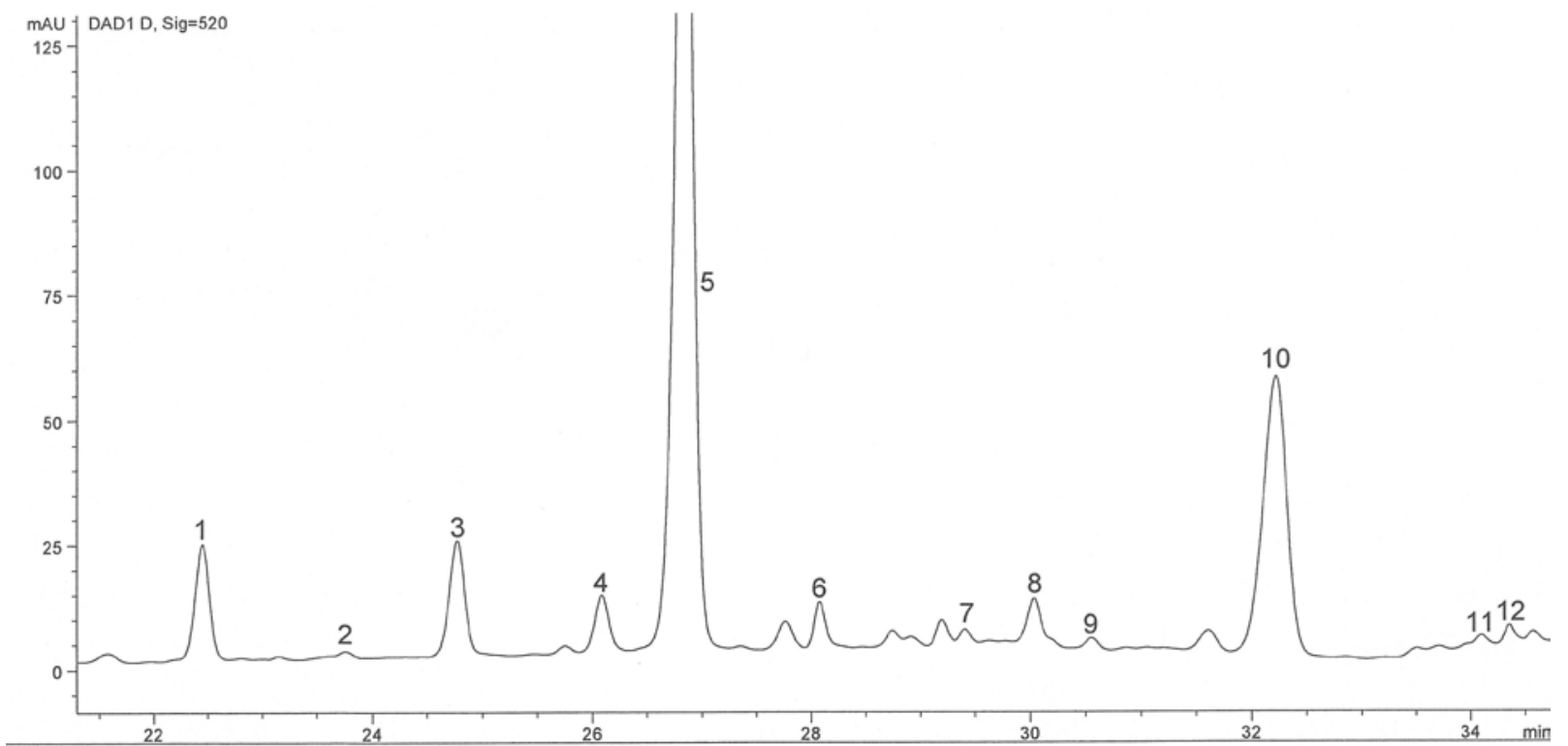

The quantification of results for anthocyanin derivatives in the analyzed samples is shown in Table 3. In Vitis vinifera L. red cultivars there are only delphinidin (Dp), cyanidin (Cy), petunidin (Pt), peonidin (Pn) and malvidin (Mv)-3-glucosides, along with the corresponding acetyl, p-coumaryl derivatives. Cyanidin is the precursor pigment of the other anthocyanidins, and it can be transformed into peonidin by the action of a 3 -O-methyltransferase, or into delphinidin by the action of a 3 `-

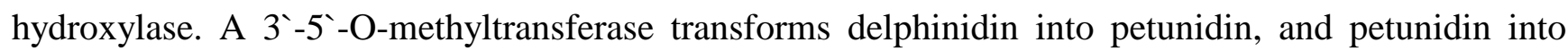
malvidin [19].

Table 3. Content of individual anthocyanins and total anthocyanin content of the wines samples (mg/L $\pm \mathrm{SD}, n=3)$.

\begin{tabular}{|c|c|c|c|c|c|c|c|c|}
\hline \multirow[b]{2}{*}{ Antocy. } & \multicolumn{8}{|c|}{ W. code } \\
\hline & $\mathbf{I}$ & II & III & IV & $\mathbf{V}$ & VI & VII & VIII \\
\hline Dp-3-gl (1) & $\begin{array}{l}21.50 \pm \\
0.17\end{array}$ & $\begin{array}{l}24.67 \pm \\
0.21\end{array}$ & $\begin{array}{l}18.48 \pm \\
0.67\end{array}$ & $\begin{array}{l}20.20 \pm \\
0.87\end{array}$ & $\begin{array}{l}83.86 \pm \\
0.45\end{array}$ & $\begin{array}{l}10.63 \pm \\
1.09\end{array}$ & $\begin{array}{l}37.39 \pm \\
1.54\end{array}$ & $\begin{array}{l}7.02 \pm \\
1.09\end{array}$ \\
\hline Cy-3-gl (2) & n.d. & n.d. & $\begin{array}{l}6.75 \pm \\
0.99\end{array}$ & $\begin{array}{l}9.26 \pm \\
1.11\end{array}$ & $\begin{array}{l}6.17 \pm \\
0.98\end{array}$ & $\begin{array}{l}7.33 \pm \\
1.12\end{array}$ & n.d. & n.d. \\
\hline Pt-3-gl (3) & $\begin{array}{l}27.61 \pm \\
1.02\end{array}$ & $\begin{array}{l}32.80 \pm \\
0.95\end{array}$ & $\begin{array}{l}34.48 \pm \\
1.76\end{array}$ & $\begin{array}{l}29.85 \pm \\
0.97\end{array}$ & $\begin{array}{l}87.83 \pm \\
0.45\end{array}$ & $\begin{array}{l}14.48 \pm \\
0.20\end{array}$ & $\begin{array}{l}41.55 \pm \\
0.91\end{array}$ & $12.97 \pm 65$ \\
\hline Pn-3-gl (4) & $\begin{array}{l}22.44 \pm \\
0.05\end{array}$ & $\begin{array}{l}10.81 \pm \\
0.86\end{array}$ & $\begin{array}{l}35.87 \pm \\
2.00\end{array}$ & $\begin{array}{l}30.47 \pm \\
0.34\end{array}$ & $\begin{array}{l}44.25 \pm \\
0.67\end{array}$ & $\begin{array}{l}10.59 \pm \\
0.44\end{array}$ & $\begin{array}{l}30.19 \pm \\
1.23\end{array}$ & $\begin{array}{l}5.43 \pm \\
0.43\end{array}$ \\
\hline Mv-3-gl (5) & $\begin{array}{l}300.62 \pm \\
0.01\end{array}$ & $\begin{array}{l}248.24 \pm \\
1.10\end{array}$ & $\begin{array}{l}249.19 \pm \\
1.97\end{array}$ & $\begin{array}{l}187.11 \pm \\
1.09\end{array}$ & $\begin{array}{l}883.13 \pm \\
0.99\end{array}$ & $\begin{array}{l}103.04 \pm \\
0.56\end{array}$ & $\begin{array}{l}461.90 \pm \\
1.05\end{array}$ & $\begin{array}{l}168.52 \pm \\
0.97\end{array}$ \\
\hline $\begin{array}{l}\text { Dp-3-gl- ac } \\
\text { (6) }\end{array}$ & $\begin{array}{l}18.15 \pm \\
1.11\end{array}$ & $\begin{array}{l}12.14 \pm \\
1.02\end{array}$ & $\begin{array}{l}16.96 \pm \\
1.56\end{array}$ & $\begin{array}{l}24.32 \pm \\
1.12\end{array}$ & $\begin{array}{l}28.52 \pm \\
0.78\end{array}$ & $\begin{array}{l}4.24 \pm \\
0.95\end{array}$ & $\begin{array}{l}15.00 \pm \\
1.01\end{array}$ & $\begin{array}{l}36.86 \pm \\
0.45\end{array}$ \\
\hline $\begin{array}{l}\text { Cy-3-gl- ac } \\
\text { (7) }\end{array}$ & $8.97 \pm 0.55$ & $\begin{array}{l}6.60 \pm \\
1.45\end{array}$ & $\begin{array}{l}6.64 \pm \\
0.67\end{array}$ & $\begin{array}{l}9.94 \pm \\
0.31\end{array}$ & $\begin{array}{l}15.15 \pm \\
0.55\end{array}$ & $\begin{array}{l}5.95 \pm \\
0.97\end{array}$ & $\begin{array}{l}9.35 \pm \\
0.97\end{array}$ & $\begin{array}{l}23.09 \pm \\
1.14\end{array}$ \\
\hline
\end{tabular}


Table 3. Cont.

\begin{tabular}{lllllllll}
\hline Pt-3-gl -ac (8) & $8.83 \pm$ & $9.10 \pm$ & $8.57 \pm$ & $9.40 \pm$ & $45.48 \pm$ & $6.86 \pm$ & $16.25 \pm$ & $8.30 \pm$ \\
& 0.65 & 0.65 & 0.97 & 0.75 & 1.04 & 0.35 & 0.23 & 1.25 \\
Pn-3-gl- & $7.28 \pm$ & $5.50 \pm$ & $11.27 \pm$ & $8.02 \pm$ & $10.03 \pm$ & $3.10 \pm$ & $11.10 \pm$ & n.d. \\
ac (9) & 0.75 & 0.97 & 1.43 & 0.98 & 1.10 & 0.13 & 0.75 & \\
Mv-3-gl-ac & $96.87 \pm$ & $56.04 \pm$ & $46.20 \pm$ & $49.45 \pm$ & $319.03 \pm$ & $32.43 \pm$ & $149.75 \pm$ & $87.17 \pm$ \\
$(10)$ & 0.23 & 1.15 & 2.03 & 1.09 & 1.09 & 0.99 & 0.66 & 0.95 \\
Pt-3-gl- p-co ( & $18.63 \pm$ & n.d. & $17.42 \pm$ & $11.23 \pm$ & $31.38 \pm$ & $7.81 \pm$ & $10.53 \pm$ & n.d. \\
11) & 0.43 & & 1.23 & 1.23 & 0.99 & 1.08 & 0.56 & \\
Pn-3-gl- & $9.53 \pm$ & $5.47 \pm$ & $15.26 \pm$ & $12.81 \pm$ & $44.03 \pm$ & n.d. & $11.77 \pm$ & n.d. \\
p-co (12) & 0.02 & 1.23 & 1.95 & 1.43 & 0.87 & & 0.78 & \\
Mv-3-gl- p-co & $40.07 \pm$ & $18.77 \pm$ & $38.18 \pm$ & $22.59 \pm$ & $138.53 \pm$ & $13.29 \pm$ & $39.06 \pm$ & $9.53 \pm$ \\
(13) & 0.05 & 0.67 & 0.67 & 0.56 & 0.98 & 1.09 & 1.07 & 0.89 \\
Sum-3-gl & $372.18 \pm$ & $316.52 \pm$ & $344.78 \pm$ & $276.89 \pm$ & $1175.03 \pm$ & $146.07 \pm$ & $570.03 \pm$ & $186.92 \pm$ \\
& 0.12 & 1.85 & 1.35 & 0.54 & 3.12 & 1.21 & 0.98 & 1.65 \\
Sum-3-gl-ac & $140.10 \pm$ & $89.38 \pm$ & $89.64 \pm$ & $101.13 \pm$ & $418.21 \pm$ & $52.58 \pm$ & $201.45 \pm$ & $68.34 \pm$ \\
& 2.05 & 2.57 & 3.10 & 1.97 & 2.14 & 1.13 & 1.98 & 2.05 \\
Sum-3-gl-p-co & $68.23 \pm$ & $24.24 \pm$ & $70.86 \pm$ & $46.63 \pm$ & $213.94 \pm$ & $21.10 \pm$ & $61.36 \pm$ & $9.53 \pm$ \\
& 3.09 & 3.10 & 2.15 & 2.76 & 2.00 & 2.12 & 2.00 & 1.15 \\
\hline
\end{tabular}

Dp-, Cy-, Pt-, Pn-, Mv-: delphinidin-, cyanidin-, petunidin-, peonidin- and malvidin-3monoglucoside; -ac: -acetate; p-coum: -p-coumarate, respectively. Sum-3-gl: sum of non-acylated anthocyanins; sum-3-gl-ac: sum of acetates and sum-3-gl-co: sum of p-coumarates. The symbol n.d.: not detected.

Quantitatively, the content of glucosylated antocyanins was predominant in the investigated Cabernet Sauvignon wines (mean amount of content was $423.55 \mathrm{mg} / \mathrm{L}$ - from 146.07 to $1175.03 \mathrm{mg} / \mathrm{L}$ ), followed by the content of acetylated ones (mean amount was $145.10 \mathrm{mg} / \mathrm{L}$ - from 52.58 to $418.21 \mathrm{mg} / \mathrm{L}$ ) and the content of $p$-coumarylated ones (mean amount was $64.49 \mathrm{mg} / \mathrm{L}$ - from 9.53 to $213.94 \mathrm{mg} / \mathrm{L}$ ). The contribution of each anthocyanin to the final anthocyanin profile was calculated based on the monoglucoside forms and is expressed as percentage in Table 4.

Table 4. Distribution of individual anthocyanins and total anthocyanin contents of the wines samples ( $\% \pm \mathrm{SD}, n=3)$.

\begin{tabular}{lllllllll}
\hline \multirow{2}{*}{ Anthoc. } & \multicolumn{7}{c}{ W. code } \\
\cline { 2 - 8 } & I & II & III & IV & V & VI & VII & VIII \\
\hline Dp-3-gl & $3.62 \pm$ & $5.81 \pm$ & $3.66 \pm$ & $4.96 \pm$ & $4.32 \pm$ & $5.17 \pm$ & $4.40 \pm$ & $2.09 \pm$ \\
$(1)$ & 0.21 & 0.45 & 0.23 & 0.55 & 0.12 & 0.11 & 0.23 & 0.13 \\
Cy-3-gl & n.d. & n.d. & $1.33 \pm$ & $2.27 \pm$ & $0.32 \pm$ & $3.57 \pm$ & n.d. & n.d. \\
$(2)$ & & & 0.07 & 0.09 & 0.02 & 0.09 & & \\
Pt-3-gl & $4.65 \pm$ & $7.72 \pm$ & $6.83 \pm$ & $7.33 \pm$ & $4.53 \pm$ & $7.04 \pm$ & $4.89 \pm$ & $3.87 \pm$ \\
$(3)$ & 0.01 & 1.02 & 0.06 & 0.10 & 0.06 & 0.04 & 0.96 & 0.06 \\
Pn-3-gl & $3.78 \pm$ & $2.55 \pm$ & $7.10 \pm$ & $7.48 \pm$ & $2.28 \pm$ & $5.15 \pm$ & $3.55 \pm$ & $1.62 \pm$ \\
$(4)$ & 0.04 & 0.90 & 0.15 & 0.15 & 0.18 & 0.55 & 0.85 & 0.01 \\
\hline
\end{tabular}


Table 4. Cont.

\begin{tabular}{lllllllll}
\hline Mv-3-gl & $50.66 \pm$ & $58.46 \pm$ & $49.33 \pm$ & $45.93 \pm$ & $45.36 \pm$ & $50.12 \pm$ & $54.43 \pm$ & $50.24 \pm$ \\
(5) & 0.10 & 0.21 & 0.16 & 0.55 & 0.15 & 0.56 & 0.06 & 1.09 \\
Dp-3-gl & $3.06 \pm$ & $2.86 \pm$ & $3.36 \pm$ & $5.96 \pm$ & $1.47 \pm$ & $2.06 \pm$ & $1.76 \pm$ & $10.99 \pm$ \\
(6) & 0.05 & 0.55 & 0.45 & 0.23 & 0.92 & 0.09 & 0.05 & 0.98 \\
Cy-3-gl- & $1.51 \pm$ & $1.55 \pm$ & $1,31 \pm$ & $2.43 \pm$ & $0.78 \pm$ & $2.89 \pm$ & $1.10 \pm$ & $6.88 \pm$ \\
ac (7) & 0.03 & 0.43 & 1.02 & 0.12 & 1.00 & 0.05 & 0.02 & 1.02 \\
Pt-3-gl- & $1.49 \pm$ & $2.14 \pm$ & $1.70 \pm$ & $2.30 \pm$ & $2.34 \pm$ & $3.34 \pm$ & $1.91 \pm$ & $2.47 \pm$ \\
ac (8) & 0.10 & 1.02 & 0.91 & 0.16 & 0.96 & 0.06 & 0.01 & 0.14 \\
Pn-3-gl- & $1.23 \pm$ & $1.30 \pm$ & $2.23 \pm$ & $1.96 \pm$ & $0.52 \pm$ & $1.51 \pm$ & $1.31 \pm$ & n.d. \\
ac (9) & 0.40 & 1.00 & 0.23 & 0.05 & 0.55 & 0.04 & 0.02 & \\
Mv-3-gl- & $16.33 \pm$ & $13.20 \pm$ & $9.15 \pm$ & $12.11 \pm$ & $16.44 \pm$ & $15.77 \pm$ & $17.62 \pm$ & $25.99 \pm$ \\
ac (10) & 0.12 & 1.09 & 0.07 & 0.17 & 0.17 & 0.45 & 0.05 & 0.06 \\
Pt-3-gl- & $3.14 \pm$ & n.d. & $3.45 \pm$ & $2.75 \pm$ & $1.62 \pm$ & $3.80 \pm$ & $1.24 \pm$ & n.d \\
p-co (11) & 0.05 & & 0.00 & 0.03 & 0.11 & 0.58 & 0.55 & \\
Pn-3-gl- & $1.61 \pm$ & $1.29 \pm$ & $3.02 \pm$ & $3.14 \pm$ & $2.27 \pm$ & n.d. & $1.38 \pm$ & n.d. \\
p-co (12) & 0.07 & 0.08 & 0.05 & 0.01 & 0.08 & & 0.23 & \\
Mv-3-gl- & $6.75 \pm$ & $4.42 \pm$ & $7.56 \pm$ & $5.53 \pm$ & $7.14 \pm$ & $6.46 \pm$ & $4.59 \pm$ & $2.84 \pm$ \\
p-co (13) & 0.06 & 0.06 & 0.17 & 0.05 & 0.05 & 1.02 & 0.12 & 0.89 \\
Sum-3-gl & $63.22 \pm$ & $74.53 \pm$ & $68.25 \pm$ & $67.82 \pm$ & $60.56 \pm$ & $71.05 \pm$ & $67.06 \pm$ & $55.72 \pm$ \\
& 0.15 & 0.09 & 0.45 & 0.67 & 0.56 & 0.55 & 0.78 & 0.09 \\
Sum-3-gl & $23.61 \pm$ & $21.05 \pm$ & $17.74 \pm$ & $24.77 \pm$ & $21.55 \pm$ & $25.58 \pm$ & $23.70 \pm$ & $20.37 \pm$ \\
-ac & 0.12 & 0.11 & 1.01 & 0.96 & 0.06 & 0.95 & 0.98 & 0.21 \\
Sum-3- & $11.50 \pm$ & $5.71 \pm$ & $14.03 \pm$ & $11.42 \pm$ & $11.03 \pm$ & $10.26 \pm$ & $7.22 \pm$ & $2.84 \pm$ \\
gl-p-co & 0.22 & 0.10 & 1.05 & 1.09 & 0.66 & 1.00 & 1.09 & 0.23 \\
\hline
\end{tabular}

Dp-, Cy-, Pt-, Pn-, Mv-: delphinidin-, cyanidin-, petunidin-, peonidin- and malvidin-3monoglucoside; -ac: -acetate; p-coum: -p-coumarate, respectively. Sum-3-gl: sum of non-acylated anthocyanins; sum-3-gl-ac: sum of acetates and sum-3-gl-co: sum of p-coumarates. The symbol n.d.: not detected.

The distribution of the most common anthocyanins in the investigated Cabernet Sauvignon wines also is depending of the microclimatic factors of region and winemaking technique: Delphinidin- was determined from 2.09 to $5.81 \%$ (mean 3.95\%); Cyanidin- varied from 0.32 to $3.57 \%$ (mean 1.94\%); Petunidin- was determined from 3.38 to $7.33 \%$ (mean 5.85\%) and peonidin-3-O-glucoside varied from 1.62 to $7.48 \%$ (mean $4.55 \%$ ). The most prominent anthocyanin was malvidin-3-O-monoglucoside, which accounted for $50.57 \%$ (from 45.36 to $58.46 \%$ ) of total content, followed by its acetyl derivatives, $15.45 \%$ (from 9.15 to 25.99\%) and p-coumaryl derivatives 5.66\% (from 2.84 to $7.56 \%$ ) in all investigated Cabernet Sauvignon wines.

The findings showed that malvidin-3-O-monoglucoside was the most abundant anthocyanin in all wines that had a prevalence of tri-hydroxylated anthocyanins. By contrast, cyanidin was the least abundant anthocyanin pigment, as demonstrated for a number of other wines [12-18,26]. A similar profile has been reported for Syrah [18,22], Hellenic native grape varieties [12], and Corsica red wines [13], but different patterns were observed for Cabernet Franc and Pinot Noir wines from British 
Columbia [3]. Another point worth mentioning is that the order of abundances based on average value of distribution for each anthocyanin was the following:

$$
\text { Mvgl > Mvgl-ac > Ptgl > Pngl > Dpgl > Mvgl-p-coum > Cygl }
$$

The Cabernet Sauvignon wines have a percentage of methoxylated (peonidin, petunidin and malvidin, sum 62.54\%) higher than non-methoxylated (cyanidin and delphinidin, sum 6.12\%) anthocyanin forms. With regard to the acylation of the glycosyl group, the distribution of non-acylated anthocyanins, mean $66.03 \%$ (from 55.72 to $74.53 \%$ ) were the most abundant fraction in all wine samples. The mean amount of contribution of acetylated anthocyanins was $22.30 \%$ (from 17.74 to $25.58 \%$ ), followed by coumarylated $9.25 \%$ (from 2.84 to $14.03 \%$ ) in all wines. According to the wine sample results, it is obviously that the content of anthocyanin constituents of single-cultivar wines coming from different viticulture regions and wine producers were different, which may be related to the thickness of the grape skin, the climate that the grape grows in, the degree of ripeness of the grape, the application of different vinification techniques and the wine's ages [1,2,29].

\subsection{The correlation between the radical scavenging activity and anthocyanin derivatives of the Cabernet Sauvignon wine samples}

The antioxidant activity of the wine samples was estimated by the ability of the sample to scavenge the stable $\mathrm{DPPH}$ • free radical $[10,16,23,24]$. The decrease in absorbance at $517 \mathrm{~nm}$ is taken as a measure of the extent of radical-scavenging. All wines show a higher $\mathrm{DPPH} \bullet$ radical scavenging activity (Table 2) in the range from 70.03 to $83.53 \%$ (mean 73.76\%). Anthocyanins are considered very good antioxidant agents, their high activity being attributed to their peculiar structure, namely the oxonium ion in the $\mathrm{C}$ ring [24]. But the number of sugar residues at the 3-position, the oxidation state of the $\mathrm{C}$ ring [25], the hydroxylation and methylation pattern, as well as the acylation by phenolic acids [16] are considered crucial factors for the expression of antioxidant effects.

The percentage of DPPH radical scavenging activity against the content of the total anthocyanins, the sum of 3-monoglucoside, the sum of 3-acetyl-3-glucoside and the sum of p-coumaryl-3-glucoside of wine samples are plotted in Figures 2 to 5.

Figure 2. Relationship between radical scavenging activity and total anthocyanins of selected Cabernet Sauvignon wine samples. 


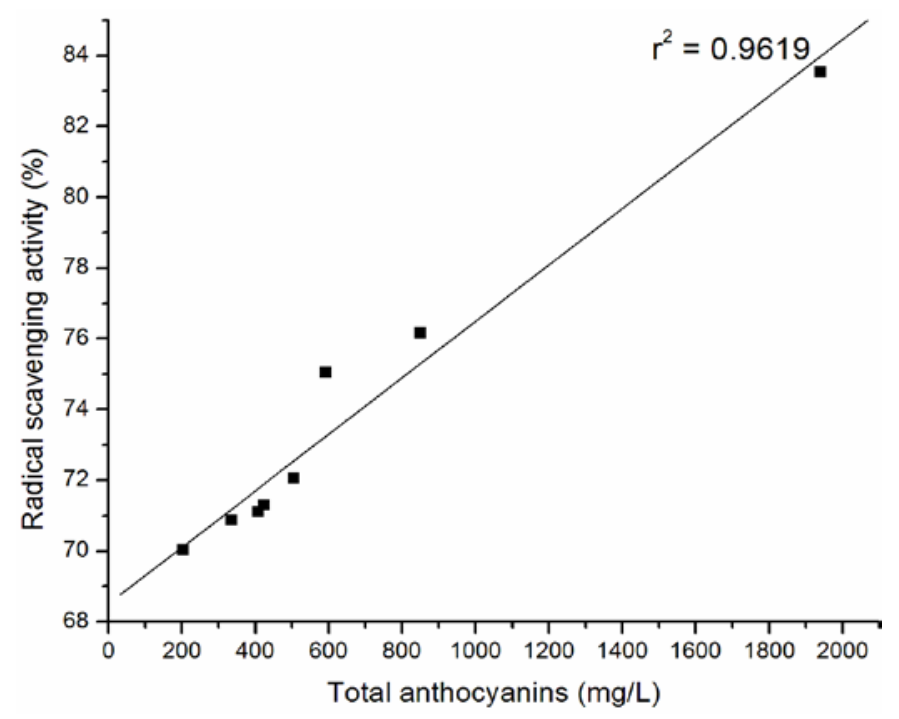

Figure 3. Relationship between radical scavenging activity and sum of non-acylated anthocyanins of selected Cabernet Sauvignon wine samples.

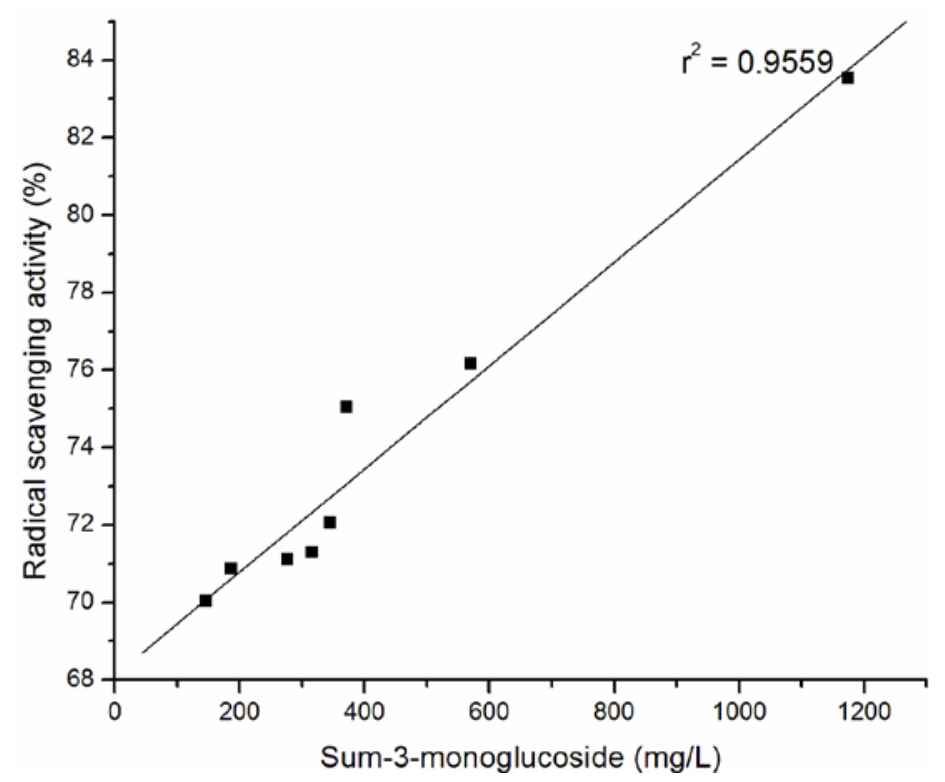

The strong correlation between total anthocyanins and DPPHscavenging ability $\left(\mathrm{r}^{2}=0.9619\right)$ of tested wines was confirmed. The significant correlations were obtained between antiradical activity and the sum of 3-monoglucoside $\left(r^{2}=0.95594\right)$, the sum of 3- acetyl-3-glucoside $\left(r^{2}=0.9728\right)$ and the sum of p-coumaryl-3-glucoside $\left(r^{2}=0.8873\right)$ of wine samples. 
Figure 4. Relationship between radical scavenging activity and sum of glucoside-acetates of selected Cabernet Sauvignon wine samples.

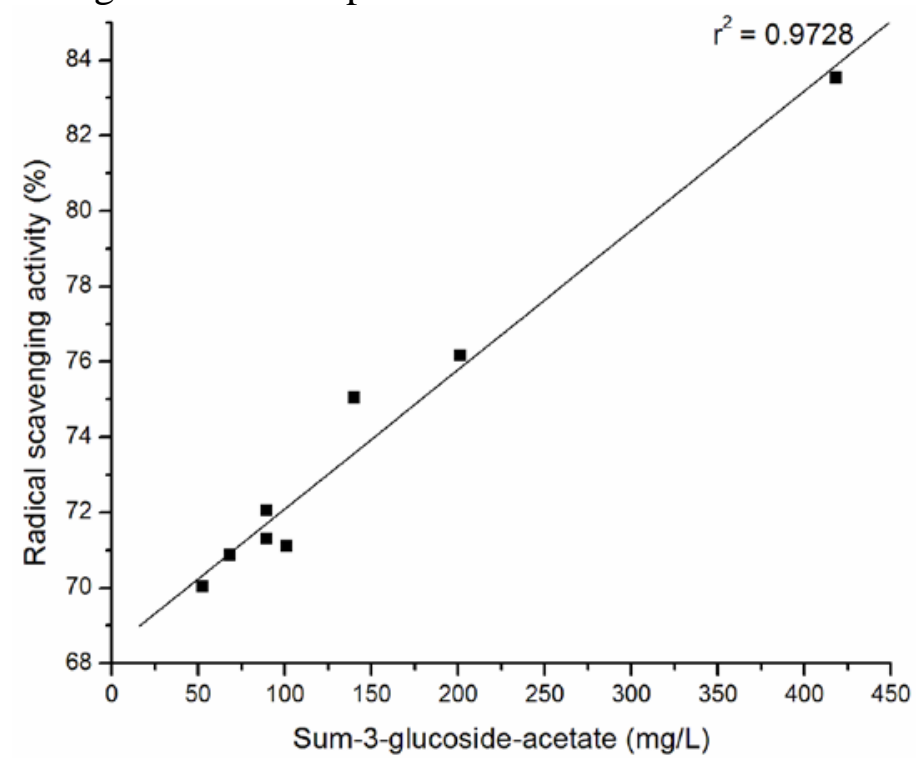

Figure 5. Relationship between radical scavenging activity and sum of glucoside-pcoumarates of selected Cabernet Sauvignon wine samples

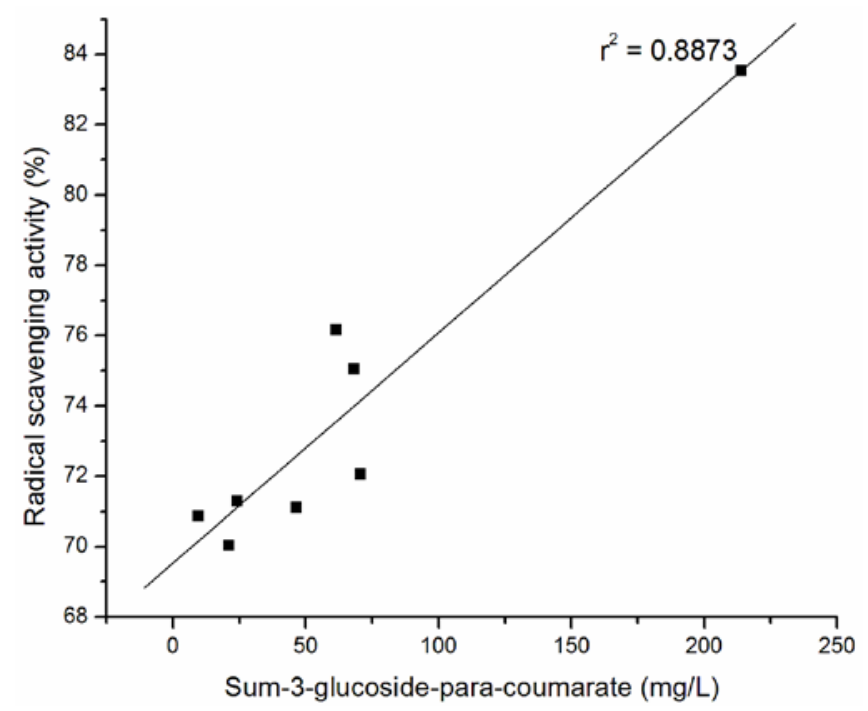

\section{Experimental}

\subsection{Materials}

Acetonitrile and acetic acid of HPLC-grade were obtained from Merck (Darmstadt, Germany); HPLC-grade methanol was purchased from Carlo Erba Reagent (Milan, Italy). Potassium metabisulfite was purchased from Merck (Darmstadt, Germany); 2,2`-diphenyl-1-picrylhydrazyl (DPPH) free radical was obtained from Sigma Chemical Co. (St. Louis, MO); Malvidin-3-monoglucoside 
chloride (oenin chloride ref. 0911S) from Extrasynthese (Genay, France). The used reagents were of analytical quality.

\subsection{Wine samples}

Eight selected Cabernet Sauvignon wines with definite geographical origin, from the 2007 and 2008 vintage seasons, produced from different agronomical and winemaking regions in the Balkans, were analyzed. All of them are listed in Table 1.

\subsection{Determination of indices for anthocyanin pigment degradation, polymeric color, browning, and} hue

Indices for anthocyanin degradation of the wine can be derived using the pH-differential method described by Giusti and Wrolstad [21]. The absorbance at $420 \mathrm{~nm}$ of the disulphide treated sample serves as an index for browning. The color density of the control sample and the polymer color of the disulphide bleached sample wine are calculated as follows:

$$
\text { Color density }=\left[\left(A_{420 \mathrm{~nm}}-A_{700 \mathrm{~nm}}\right)+\left(A \lambda_{\max }-A_{700 \mathrm{~nm}}\right)\right]
$$

The value of hue is calculated as follows:

$$
\text { Hue }=\left[\left(A_{420 \mathrm{~nm}}-A_{700 \mathrm{~nm}}\right) /\left(A \lambda_{\max }-A_{700 \mathrm{~nm}}\right)\right]
$$

The ratio between polymeration color and color density is used to determine the percentage of the color that is contributed by polymerized material:

$$
\text { Polymeric color }(\%)=(\text { polymeric color/color density }) \times 100
$$

\subsection{Free radical scavenging activity}

The free radical scavenging activity of the wine samples was analyzed by using the 2,2'-diphenyl-1picrylhydrazyl $\left(\mathrm{DPPH}^{\bullet}\right)$ assay $[10,23,24]$ for antioxidant activity which is based on measurement of the loss of $\mathrm{DPPH}^{\bullet}$ color by change of absorbance at $517 \mathrm{~nm}$ caused by the reaction of $\mathrm{DPPH}^{\bullet}$ with tested wine sample. The reaction was monitored by a UV/VIS spectrophotometer. The diluted wine sample (wine was diluted with water, 1:10 v/v) and fresh $1 \times 10^{-4} \mathrm{M} \mathrm{DPPH}^{\bullet}$ metabolic solution were putted into a cuvette at the room temperature. After 20 min incubation period at room temperature, the absorbance was read against a blank at $517 \mathrm{~nm}$. Scavenging capacity of $\mathrm{DPPH}^{\bullet}$ in percent (\%) of each wine sample was calculated from the decrease of absorbance according to the relationship:

$$
\text { Radical scavenging activity }(\%)=\left(1-A_{\text {sample }}-A_{\text {blank }} / A_{\text {control }}\right) \times 100
$$

where $A_{\text {control }}$ is the absorbance of control reaction ( $3 \times 10^{-4} \mathrm{M} \mathrm{DPPH} \bullet$ solution), $A_{\text {blank }}$ is the absorbance of dilution wine sample and $A_{\text {sample }}$ is the absorbance of the dilution wine sample with same concentration of DPPH• solution. Three analytical replicates were carried out on each sample wine. 


\subsection{High performance liquid chromatography (HPLC-DAD) analysis}

Anthocyanins were analyzed by direct injection of the samples, previously filtered through a $0.45 \mu \mathrm{m}$ pore size membrane filter, in an Agilent Technologies 1200 chromatographic system equipped with a Agilent photodiode array detector (DAD) 1200 with RFID tracking technology for flow cells and UV lamp, an automatic injector, and a ChemStation software. The column was termostated at 30 ${ }^{\circ} \mathrm{C}$. After injecting $5 \mu \mathrm{L}$ of wine sample, separation was performed in an Agilent-Eclipse XDB C-18 $4.6 \times 150 \mathrm{~mm}$ coumn. The HPLC grade solvents used were formic acid/water as solvent $\mathrm{A}$ and acetonitrile/formic acid/water as solvent $\mathrm{B}$. The elution profile was as follows: from 0 to $28 \mathrm{~min}, 0.0 \%$ B, from 28 to $35 \mathrm{~min}, 25 \% \mathrm{~B}$, from 35 to $40 \mathrm{~min}, 50 \% \mathrm{~B}$, from 40 to $45 \mathrm{~min}, 80 \% \mathrm{~B}$, and for last 10 min again $0 \% \mathrm{~B}$. The detection wavelength was $520 \mathrm{~nm}$. The different anthocyanin compounds were identified by comparing their retention times and spectral characteristics with data given in the literature $[18,20,27,28]$. Quantitation was made by means of a calibration curve obtained by injecting standard solutions of malvidin-3-monoglucoside chloride with different concentrations. The range of the linear calibration curve $\left(r^{2}\right.$ was 0.9991). Results were expressed as mg/L sample.

\subsection{Statistical analyses}

Three analytical replicates were carried out on each sample wine. Measurements were averaged, and results are given as mean \pm standard deviation (SD). Correlation between the anthocyanin content and antiradical efficiency was established using regression analysis at a 95\% significance level $(\mathrm{P} \leq 0.001)$.

\section{Conclusions}

From the results obtained, we can conclude that the amount of anthocyanins is important for understanding of antioxidant potency of red wines. The mechanism by which anthocyanins are absorbed and metabolized in the body is currently unclear. The high anthocyanin content in the investigated Cabernet Sauvignon wines contributes to its increased radical scavenging activity. It can be concluded that, the anthocyanin composition can be used as biochemical marker for the authenticity of red grape cultivar and their corresponding single-cultivar wine.

\section{Acknowledgements}

The research was supported by the Europe Union, FP7 - REGPOT - 2007- 3-01, KBBE: Food, Agriculture, and Biotechnology, Project «Chromlab-Antioxidant», No. 204756.

\section{References}

1. Crippen, D.D.; Morrison, J.C. The effects of sun exposure on the compositional development of Cabernet Sauvignon berries. Am. J. Enol. Vitic. 1986, 37, 235-247.

2. Gey, K.F. The antioxidant hypothesis of cardiovascular disease: Epidemiology and mechanisms. Biochem. Soc. Trans. 1990, 18, 1041-1045. 
3. Mazza, G.; Fukumoto, L.; Delaquis, P.; Girard, B.; Ewert, B. Anthocyanins, Phenolics, and Color of Cabernet Franc, Merlot, and Pinot Noir Wines from British Columbia. J. Agric. Food Chem. 1999, 47, 4009-4017.

4. Renaud, S; de Lorgeril M. Wine, alcohol, plateles and the French paradox for conorary heart disease. Lancet 1992, 339, 1523-1526.

5. Lila, M.A. Anthocyanins and human health: In vitro investigative approach. J. Biomed. Biotech. 2004, 5, 306-313

6. Tsuda, T.; Horio, F.; Osawa, T. The role of anthocyanins as an antioxidant under oxidative stress in rats. Biofactors 2000, 13, 133-139.

7. Hou, D.X. Potential mechanisms of cancer chemoprevention by anthocyanins. Curr. Mol. Med. 2003, 3, 149-159.

8. Daglia, M.; Papeti, A.; Grisoli, P.; Aceti, C.; Dacarro, C.; Gazzani, G. Antibacterial activity of red and white wine against oral Streptococci. J. Agric. Food Chem. 2007, 55, 5038-5042.

9. De Beer, D.; Joubert, E.; Gelderblom, W.C.A.; Manley, M. Antioxidant activity of South African red and white cultivar wines: Free radical scavenging. J. Agric. Food Chem. 2003, 51, 902-909.

10. Radovanović, A.; Radovanović, B.; Jovančičević, B. Free radical scavenging and antibacterial activities of southern Serbian red wines. Food Chem. 2008, 117, 326-333.

11. Sugita-Konishi, Y.; Hara-Kudo, Y.; Iwamoto, T.; Kondo, K. Wine has activity against enteropathogenic bacteria in vitro but not in vivo. Biosci. Biotechnol. Biochem. 2001, 65, 954-957.

12. Kallithraka, S.; Mohdaly, A.A.; Makris, D.P.; Kefalas, P. Determination of major anthocyanin pigment in Hellenic native grape varieties (Vitis vinifera sp.): Association with antiradical activity. J. Food Comp. Anal. 2007, 18, 375-386.

13. Franco, M.A.; Sterlazzo, G.; Bagard, A.; Coloru, G.C.; Manca, G. Multivariate statistical techniques applied to anthocyaninic profile of red grapes cultivar harvested from Corsica. J. Commodity Sci. 1998, 37, 83-94.

14. Heredia, F.J.; Francia-Aricha, E.; Rivas-Gonzalo, J.C.; Vicario, I.M.; Santos-Buelga, C. Chromatic characterization of anthocyanins from red grapes. I. pH effect. Food Chem. 1998, 63, 491-498.

15. Munoz-Espada, A.C.; Wood, K.V.; Bordelon, B.; Watkins, B.A. Anthocyanin Quantification and radical scavenging capacity of Concord, Norton and Marechal Foch grapes and wines. J. Agric. Food Chem. 2004, 52, 6779-6786.

16. Degenhardt, A.; Knapp, H.; Winterhalter, P. Separation and purification of anthocyanins by highspeed counter current chromatography and screening for antioxidant activity. J. Agric. Food Chem. 2000, 48, 1063-1072.

17. Esteban, M.A.; Villanueva, M.J.; Lissarrague, J.R. Effect of irrigation on changes in the anthocyanin composition of the skin of $\mathrm{cv}$ tempranillo (Vitis vinifera L.) grape berries during ripening. J. Sci. Food Agric. 2001, 81, 409-420.

18. Gomez-Miguez, M.; Gonzalez-Miret, L.M.; Heredia, F.J. Evolution of colour and anthocyanin composition of Syrah wines elaborated with prefermentative cold maceration. J. Food Engin. 2007, 79, 271-278. 
19. Vivar-Quintana, A.M.; Santos-Buelga, C.; Rivas-Gonzalo, J.C. Anthocyanin-derived pigments and colour of red wines. Anal. Chim. Acta 2002, 458, 147-155.

20. Harborne, J.B.; Williams, C.A. Anthocyanins and other flavonoids. Nat. Prod. Rep. 2001, 18, 310-333.

21. Guisti, M.; Wrolstad, R. Characterization and measurement of anthocyanins by UV-Visible spectroscopy. In Current Protocols in Food Analytical Chemistry; John Wiley and Sons: New York, NY, USA, 2003; p. 233.

22. Roggero, J.P.; Coen, S.; Ragonnet, B. High performance liquid chromatography survey on changes in pigment content in ripening grapes of Syrah. Amer. J. Enol. Vitic. 1986, 37, 77-83.

23. Roussis, I.G.; Lambropoulos, I.; Soulti, K. Scaveringing capacities of some wines and wine phenolic extracts, Food Technol. Biotechnol. 2005, 43, 351-358.

24. Wang, H.; Cao, G.; Prior, R.L. Oxygen radical absorbing capacity of anthocyanins. J. Agric. Food Chem. 1997, 50, 3495-3500

25. Lapidot, T.; Harel, S.; Akiri, B.; Granit, R.; Kanner, J. pH-dependent forms of red wine anthocyanins as antioxidants, J. Agric. Food Chem. 1999, 47, 67-70.

26. Hebrero, E.; Santos-Buelga, C.; Rivas-Gonzalo, J.C. High performance liquid chromatographydiode array spectroscopy identification of anthocyanins of Vitis vinifera variety Tempranillo. Amer. J. Enol. Vitic. 1988, 39, 227-233.

27. Revilla, E.; Ryan, J.M. Analysis of several phenolic compounds with potential antioxidant properties in grape extracts and wines by high-performance liquid chromatography-photodiode array detection without sample preparation. J. Chromatogr. A 2000, 881, 461-469.

28. Lachman, J.; Sulc, M.; Schilla, M. Comparison of the total antioxidant status of Bohemian wines during the wine-making process. Food Chem. 2007, 103, 802-807.

29. Villano, D.; Fernandez-Pachon, M.S.; Troncoso, A.M.; Garcia-Parrilla, M.C. Influence of enological practices on the antioxidant activity of wines. Food Chem. 2006, 95, 394-404.

Sample Availability: Samples of the compounds are available from the authors.

(C) 2010 by the authors; licensee MDPI, Basel, Switzerland. This article is an Open Access article distributed under the terms and conditions of the Creative Commons Attribution license (http://creativecommons.org/licenses/by/3.0/). 